\title{
A Influência das Avaliações de Fornecedores na Rescisão de Contratos de Serviços de Exploração e Produção de Petróleo e Gás no Brasil
}

\begin{abstract}
Resumo
A literatura de avaliação de desempenho de fornecedores aponta que a prévia identificação de contratos considerados insatisfatórios pode se revelar crucial para a manutenção de uma empresa, especialmente em setores com alto risco operacional, ambiental e com investimentos significativos, como é o caso do setor de exploração de petróleo e gás. Embora considerada importante, a rescisão contratual tem sido pouco estudada no segmento de petróleo brasileiro, em decorrência do baixo número de firmas que atuam no setor e da restrição de acessos às informações dessas empresas. O presente artigo tem como objetivo diminuir essa lacuna ao analisar quais critérios de avaliação de serviços mais influenciam as rescisões contratuais no setor brasileiro de exploração e produção de petróleo e gás. Para tanto, foram analisadas, via regressões logit, as avaliações dos contratos de serviços encerrados no período de 1/1/2006 a $31 / 12 / 2014$ por uma unidade de negócio que atua na exploração e produção de petróleo e gás localizada no Brasil. No banco de dados resultante, constaram-se 273 contratos que contemplam todas as especialidades de serviços da atividade, com um total de 19.613 avaliações. Os resultados indicam que os critérios Prazo e Logística são os que apresentam maior influência nas rescisões contratuais das atividades do setor. Além disso, ao segregar-se as análises por especialidades, verificou-se que diferentes especialidades possuem demandas distintas e, por conseguinte, diferentes modelos contratuais. Tais resultados corroboram empiricamente as discussões teóricas presentes na literatura acerca da importância do cumprimento das obrigações contratuais, especialmente com relação aos prazos negociados.
\end{abstract}

Palavras-chave: Avaliação de Desempenho de Fornecedores. Rescisão de Contratos de Serviços. Exploração e Produção de Petróleo e Gás.

\section{Cleison Antonio Pinto}

Mestre em Administração de Empresas, Mestrado em Administração de Empresas pela Fucape Business School e Administrador Pleno na Petróleo Brasileiro S.A. - Petrobras. Contato: Av. Nossa Sra. da Penha, 1688 , Bloco $01,5^{\circ}$ andar. Barro Vermelho. Vitória-ES, CEP : 29057-570.

E-mail: cleison.pinto@hotmail.com

Danilo Soares Monte-Mor Doutor em Administração e Ciências Contábeis pela FUCAPE Business School e Professor na Fucape Business School, Contato: Av. Fernando Ferrari, 1358. Boa Vista. Vitória-ES, CEP: 29075-505.

E-mail: danilo@fucape.br

\section{Jedson Pereira Pinto}

Mestre em Ciências Contábeis pela FUCAPE Business School e PhD Student University of North Carolina at Chapel Hill, Contato: 300 Kenan Dr 27514. Baity Hill. Chapel Hill. North Carolina. United States, CEP: 27514.

E-mail: jedson_pinto@kenan-flagler.unc.edu 


\section{Introdução}

A identificação de contratos de prestação de serviços terceirizados que apresentem desempenho insatisfatório pode se revelar crucial para a manutenção operacional das empresas contratantes (Williamson, 1985; Hart \& Moore, 1990; Tirole, 2007), especialmente em setores que requerem grandes investimentos e possuem elevados riscos operacionais, como é o caso da exploração e produção de petróleo e gás. Isso porque a suspensão de atividades por falha da empresa contratada poderá resultar em prejuízos financeiros relevantes para a contratante (Suslick, 2002; Kaiser \& Pulsipher, 2004). Por exemplo, a rescisão de um contrato de fornecimento de alimentação em uma plataforma de exploração e produção de petróleo pode acarretar a paralisação das atividades e, consequentemente, a interrupção da produção.

O encerramento da relação contratual pode ocorrer por meio do implemento de condição (Encerramento Normal), convenção entre as partes (Distrato) e falta da prestação devida (Rescisão) (Pereira, 2003; Gasparini, 2007; Di Pietro, 2008). No caso da rescisão contratual, haverá aumento nos custos de transação (Williamson, 1985; Hart \& Moore, 1990; Hart, 1999; Tirole, 2007), para a empresa contratante decorrentes da necessidade de conduzir um novo processo de contratação, além dos custos oriundos da rescisão do contrato e os seus possíveis riscos jurídicos e operacionais (Basel Committee on Banking Supervision, 2005).

Uma forma de minimizar o efeito de potenciais rescisões contratuais, bem como os custos envolvidos, seria a avaliação por meio de monitoramento periódico dos serviços prestados pelos fornecedores a partir de critérios previamente estabelecidos, tais como a confiabilidade e qualidade dos serviços prestados, custos adicionais, flexibilidade, qualidade e rapidez na entrega, etc. (Williamson, 1985; Baily, Farmer, Jones \& Jessop (2000); Slack, Chambers \& Johnston (2002); Stueland, 2004; Bowersox \& Closs, 2001).

O objetivo deste artigo é analisar a importância do monitoramento dos fornecedores (por meio das avaliações) na identificação de contratos rescindidos unilateralmente pela empresa contratante e que possivelmente incorrerão em custos de transação para a empresa. Especificamente, o trabalho procura estudar quais critérios de avaliação de fornecedores de serviços que mais influenciam as rescisões contratuais no setor de exploração e produção de petróleo e gás.

Embora seja considerado importante sob o ponto de vista financeiro e operacional das empresas, tal tópico de pesquisa tem sido pouco estudado, em decorrência do baixo número de firmas que atuam no setor (brasileiro) e da restrição de acessos às informações dessas empresas. Dentre os estudos referentes a contratos no setor de petróleo, encontram-se Kaiser e Pulsipher (2004), que investigaram o sistema fiscal contratual para o desenvolvimento de campos em águas profundas em Angola, e Coriolano, Reis e Delgado (2013) os quais discutem os modelos de contratos para exploração e produção de petróleo e gás. Entretanto, nenhum deles investigou a relação entre as avaliações dos serviços prestados e a rescisão contratual.

Para que fosse possível investigar a relação entre a avaliação de desempenho de fornecedores e a rescisão contratual, considerou-se um estudo de caso descritivo que foi analisado a partir das avaliações dos fornecedores de serviços de uma unidade de uma empresa de petróleo multinacional que opera no Brasil e em diversos outros países. O banco de dados inicial continha todos os contratos de serviços contratados e encerrados entre 1/1/2006 e 31/12/2014. Como o foco do trabalho foi a análise da relação entre as avaliações de desempenho das empresas contratadas e a rescisão contratual, foram excluídos os contratos assinados no referido período e que permaneceram vigentes a partir de 31/12/2014. No banco de dados resultante, constaram-se 273 contratos de serviços, com o total de 19.613 avaliações.

Na referida empresa, os serviços são avaliados, no mínimo, a cada trimestre por meio de pontuação objetiva em critérios como: logística (armazenamento, transportes, equipamentos e instalações), Gestão, Prazo, Qualidade, Recursos Humanos (RH) e Segurança, Meio Ambiente e Saúde (SMS). Tais critérios se assemelham aos analisados por Baily et al. (2000), Bowersox e Closs (2001) e Stueland (2004). Os critérios dessas avaliações constam nas condições do contrato, e as notas objetivas variam de 0 a 100 pontos. As pontuações dos critérios são definidas de acordo com a especialidade do serviço, e as notas atribuídas estão enquadradas nos conceitos: péssimo, insuficiente, regular, bom e excelente.

Destaca-se que as avaliações dos fornecedores são parte crucial na decisão de rescisão ou vigência do 
vínculo contratual da empresa. Nesse sentido, espera-se observar o esforço dos fornecedores para a prestação de bons serviços traduzidos em boas notas. Consequentemente, prevê-se uma relação negativa entre as notas das avaliações e a probabilidade de um contrato ser rescindo. Ou seja, contratos com maior qualidade têm menores chances de serem unilateralmente rescindidos pela empresa contratante. Neste trabalho, utilizou-se regressões logit, para que fosse possível identificar quais critérios de avaliação de fornecedores de serviços que mais influenciam as rescisões contratuais no setor de exploração e produção de petróleo e gás.

A partir dos resultados obtidos, observou-se que os critérios de avaliação de desempenho que influenciaram o aumento da probabilidade da rescisão contratual (na média e mediana) foram "Prazo" e "Logística". Esses resultados corroboram o entendimento de Suslick (2002) e Kaiser e Pulsipher (2004), no qual o segmento de exploração e produção de petróleo possui altos riscos empresariais atribuídos às incertezas quanto ao resultado, aos elevados custos e à ampla quantidade de exigências definidas em lei, ratificando a importância do cumprimento das obrigações contratuais, especialmente os prazos negociados.

Adicionalmente, foi possível observar que diferentes especialidades apresentaram demandas e gargalos peculiares, uma vez que os critérios que possuem maior impacto na probabilidade de rescisão contratual diferem entre as especialidades. Tais resultados são relevantes na medida em que podem direcionar políticas de monitoramento dos fornecedores visando minimizar potenciais rescisões contratuais e, consequentemente, maximizar a performance da firma contratante.

A relevância da análise dos contratos rescindidos fica evidente nos resultados da análise descritiva, os quais indicam elevado percentual de contratos rescindidos, sendo 7,69\% da quantidade e $10,82 \%$ nos valores dos contratos encerrados no período analisado. Também foi possível constatar que as rescisões contratuais estão concentradas nos contratos de Serviços Gerais, e Construção, Montagem e Manutenção Industrial. Vale destacar que aproximadamente $25 \%$ das avaliações da especialidade Serviços Gerais estão com resultados inferiores a 70 pontos, corroborando para justificar o grande percentual de rescisões contratuais nesse tipo de serviço. $\mathrm{Da}$ mesma forma, é possível observar que o critério Prazo teve cerca de 35\% das avaliações como insatisfatórias.

A relevância desse trabalho está na confirmação da importância do monitoramento dos agentes econômicos a fim de evitar possíveis eventos que elevem os custos de transação da empresa (neste caso, as rescisões contratuais). $\mathrm{O}$ estudo da relevância informacional está atrelado à contabilidade. Especificamente, o foco do trabalho possui base nas técnicas de contabilidade gerencial de análise de projetos (contratos) e monitoramento.

Além disso, o trabalho procura estender o entendimento da estrutura de avaliação de contratos de uma empresa de grande porte e relevância no setor econômico brasileiro. Devido à complexidade e diversidade dos contratos presentes no estudo, espera-se, por meio deste estudo de caso, colaborar para o melhor entendimento do processo de monitoramento e gerenciamento de relações contratuais. Por exemplo, os resultados (e o método utilizado) podem ajudar empresas a encontrarem possíveis direcionamentos de políticas para a melhoria na gestão dos contratos de uma empresa, uma vez que identifica quais critérios possuem maior efeito na probabilidade de um contrato ser rescindido, especificamente em uma empresa que atua no segmento de exploração e produção de petróleo e gás.

Entender e aperfeiçoar a gestão dos contratos por meio de ações que permitam reduzir as possíveis rescisões contratuais parece ser interessante para todas as empresas, corroborando Klein (1992), que afirma que a melhoria no desenho dos contratos tem potencial para reduzir a probabilidade de encerramento contratual de cunho oportunista. Os resultados sugerem possíveis direcionamentos de novas políticas para o aumento da eficiência dessa gestão, uma vez que identifica quais critérios possuem maior efeito na probabilidade de um contrato ser rescindido em uma empresa de exploração e produção de petróleo e gás.

Este trabalho está estruturado em quatro seções, além desta introdução. A próxima seção apresenta a revisão da literatura, iniciando pela descrição do processo de terceirização e prosseguindo com a abordagem de teorias, como Custos de Transação e Contratos Incompletos; já a seção 3 descreve a metodologia que foi utilizada para o presente estudo, demonstrando a forma de apuração dos dados e esclarecendo os critérios de avaliação de desempenho utilizados, além do modelo proposto com as suas variáveis dependente e independente; a seção 4 apresenta os resultados observados a partir do modelo logit, por último, a seção 5 expõe a conclusão e demais comentários. 


\section{Terceirização e a Economia dos Custos de Transação}

Fine (2000) argumenta que o desenho da cadeia de suprimentos consiste em selecionar qual atividade deve ser terceirizada para fornecedores (fazer versus comprar), escolher qual fornecedor usar (seleção de fornecedores) e negociar o contrato. Chopra (2013, p. 428), por sua vez, defende que as decisões de contratação são essenciais porque afetam o nível de eficiência e responsividade que a cadeia de suprimentos pode alcançar. De acordo com esse autor, as decisões de contratação devem ser feitas para aumentar a quantidade de excedente total a ser compartilhado pela cadeia de suprimentos.

O excedente total é afetado pelo impacto de contratação sobre vendas, serviços, e sobre custos comos os de produção, estoque, transporte e de informação. Nesses casos, a contratação de terceiros passa a ser significativa caso eleve o excedente da cadeia de suprimentos a um valor superior que o excedente gerado quando a firma verticaliza o processo produtivo (Mcivor, 2005).

Para Williamson (1985), a decisão de contratação será sempre feita em relação à possibilidade de redução de custos e à importância da especificidade dos ativos. Dentro desse contexto, a gestão eficiente de contratos de serviços ajuda a reduzir custos e melhorar a rentabilidade (compra de grandes quantidades pode proporcionar economias de escala); reduzir o desperdício por meio da seleção de insumos que produzem menos resíduos (e também menores custos); gerenciar a demanda, por exemplo, por meio do fornecimento just-in-time; melhorar o fluxo de caixa para obter melhores preços e prazos de pagamento; melhorar a eficiência, certificando-se que os fornecedores entreguem os serviços nas condições e prazos negociados; e melhorar a competitividade do negócio, buscando produtos e serviços inovadores que agreguem valor.

No presente estudo, foi utilizada a teoria da Economia dos Custos de Transação (ECT) como referência para a decisão da terceirização, pois, conforme Lacity e Hirschheim (1993), a ECT é mais utilizada para análises do processo de terceirização de serviços, principalmente para decisões de cunho econômico, em que a relação entre o custo e o benefício é considerada primordial para a escolha da empresa vencedora a ser contratada.

\subsection{A Incompletude dos Contratos e o Monitoramento Contratual}

As empresas, para atuarem no mercado, incorrem em custos de transação (Coase, 1937). Tais custos estão relacionados com a incompletude dos contratos e o comportamento oportunista dos agentes econômicos nas transações (Williamson 1985). A incompletude dos contratos se refere à impossibilidade dos principais de conseguirem prever (ex-ante) todas as situações que poderão advir durante a execução contratual (Hart \& Moore 1990; Tirole 2007 e Williamson 1985), seja pela racionalidade limitada (Williamson, 1985) ou pelos elevados custos contratuais (Hart \& Moore, 1990).

O comportamento oportunista dos agentes também afeta o custo do desenho dos contratos (Klein, 1992) e pode agravar a situação financeira de uma firma cujos contratos permitem a discricionariedade destes agentes. Visto que os custos de transação e a incompletude contratual são características inerentes aos negócios, surge a necessidade de as empresas criarem estruturas de monitoramento e de controle para mitigar potenciais custos contratuais e reduzir comportamentos oportunistas (Van De Ven, 1976; Willcoks \& Fenny, 1998).

Uma forma deste monitoramento ocorre por meio das avaliações dos fornecedores (Gomes, 2014), ou seja, por meio de um monitoramento periódico dos serviços prestados pelos fornecedores a partir de critérios previamente estabelecidos, tais como a confiabilidade e qualidade dos serviços prestados, custos adicionais, flexibilidade, qualidade e rapidez na entrega, etc. (Williamson, 1985; Baily et al., 2000; Slack et al. 2002; Stueland, 2004; Bowersox \& Closs, 2001). 


\subsection{A Rescisão Contratual}

O exemplo de custo de transação estudado neste trabalho se refere à rescisão contratual, a qual resulta, além de perdas econômicas, em custos de negociação de um novo contrato (Williamson, 1985; Hart \& Moore, 1990; Hart, 1999; Tirole, 2007). O encerramento da relação contratual dá a ideia de extinção do contrato e ocorre por meio do implemento de condição, convenção entre as partes ou falta da prestação devida (Pereira, 2003; Gasparini, 2007; Di Pietro, 2008).

O implemento de condição, ou seja, o cumprimento das condições acordadas no contrato, extingue as obrigações das partes e, por conseguinte, o próprio contrato. Neste trabalho, esses contratos serão denominados como Encerramento Normal. Já a convenção entre as partes ou resilição bilateral é o acordo firmado entre as partes contratantes para antecipar o término do contrato. Os contratos encerrados dessa forma serão chamados de Distrato. Por último, a falta de prestação devida pressupõe o não cumprimento das obrigações assumidas por uma das partes, que poderá ensejar na resolução do contrato pela outra parte. Neste trabalho, os contratos encerrados unilateralmente serão chamados de Rescisão (Gasparini, 2007; Di Pietro, 2008).

Alguns dos motivos que resultam em rescisões contratuais são: atraso injustificado no início do serviço; cumprimento irregular de obrigações; paralisação do serviço, sem justa causa; e protesto de títulos ou cheques sem suficiente provisão de fundos. A rescisão contratual poderá ensejar na responsabilização da contratada e as consequências contratuais que estão previstas em lei, além da aplicação das seguintes sanções: advertência; multa; suspensão de participação em licitação; e proibição de participar de licitação (Brasil, 1998b).

No caso da rescisão contratual, esta poderá provocar o aumento dos custos de transação (Williamson, 1985; Hart \& Moore, 1990; Tirole, 2007) para a empresa contratada, que terá custos imediatos para a desmobilização dos recursos alocados e poderá sofrer sanções definidas em lei (Brasil, 1998b). O mesmo ocorre para a empresa contratante devido à necessidade de conduzir novo processo de contratação, o qual inclui a negociação, redação do contrato e as despesas decorrentes do início desse novo contrato, além dos custos advindos da rescisão do contrato anterior e os seus possíveis riscos jurídicos e operacionais.

Segundo o Basel Committee on Banking Supervision, o risco jurídico, ou legal, inclui, mas não está limitado à exposição a multas, sanções ou indenizações decorrentes de ações judiciais, bem como de acordos extrajudiciais. Da mesma forma, define o risco operacional como sendo o risco de perdas decorrentes de processos internos falhos ou inadequados, pessoas e sistemas ou, ainda, de eventos externos (Basel Committee on Banking Supervision, 2005).

Estudos sobre a teoria dos custos transacionais e as características de contratos são encontrados especialmente em estudos de caso no setor de construção, como, por exemplo, Greenwood e Yates (2006), Eriksson (2008) e Gomes (2014). Especificamente, Greewood e Yates (2006) verificaram que relações de parcerias ajudaram a mitigar os custos transacionais advindos da incompletude contratual e o comportamento oportunista dos agentes. Por sua vez, Eriksson (2008) estudou as características dos contratos que estão ligadas à relação de parceria no setor de construção (especificidade, frequência, incerteza) e observou que estas são relevantes na hora da contratação. Estes resultados são corroborados por Gomes (2014).

Assim como no setor de petróleo, a motivação para os estudos no setor de construção se dá pela complexidade do setor alinhado aos altos custos transacionais presentes (Gomes 2014). Ressalta-se que as atividades de exploração e produção de petróleo envolvem diversos riscos geológicos, econômicos e financeiros (Nepomuceno, 2000). Como exemplo de riscos financeiros, podemos citar as cifras financeiras apresentadas pela maior operadora do Brasil, a Petrobras, que emprega alta tecnologia e recursos financeiros, com investimento previsto no quinquênio de 2014 a 2018 no valor de US $\$ 154$ bilhões (PETROBRAS, PNG 2014-2018).

Entretanto, a dificuldade de acesso a dados no setor petrolífero se revela um dos principais motivos para a falta de estudos das relações contratuais e da teoria do custo de transação, principalmente no Brasil, onde a exploração do petróleo e regulada pela Agência Nacional de Petróleo (ANP) via licitações (Brasil, 1998a). 


\section{Metodologia}

\subsection{Procedimentos de Seleção da Amostra e Design Empírico}

O estudo foi elaborado por meio de uma análise descritiva (Yin, 2001) e foi analisado com base nos procedimentos utilizados para a avaliação dos fornecedores de serviços de uma empresa multinacional de petróleo com forte atuação no Brasil e em outros países. Foi desenvolvido a partir de banco de dados composto por todos os contratos de serviços encerrados entre 1/1/2006 e 31/12/2014. Como o foco do trabalho foi a análise da influência das avaliações de desempenho dos fornecedores nas rescisões de contratos, foram excluídos os contratos assinados nesse período e que permaneceram vigentes a partir de 31/12/2014. Vale observar que todos os contratos analisados foram rescindidos unilateralmente pela empresa contratante.

A empresa analisada neste trabalho, no papel de contratante, utiliza mecanismos próprios para regular as transações (Jensen \& Meckling, 1976; Azevedo, 2000), que, no presente caso, é o acompanhamento e a monitoração dos contratos de serviços. Para isso, os serviços são avaliados por meio das avaliações de desempenho que são realizadas, obrigatoriamente, no mínimo a cada trimestre. São avaliados itens como: Gestão, Logística (armazenagem, transporte, equipamentos e instalações), Prazo, Qualidade, Recursos e Segurança, Meio Ambiente e Saúde (SMS). Tais critérios estão de acordo com os apresentados pelos autores mencionados (Williamson, 1985; Baily et al., 2000; Slack et al. 2002; Stueland, 2004; Bowersox \& Closs, 2001).

Os critérios dessas avaliações constam nas condições do contrato, bem como as notas objetivas que variam de 0 a 100 pontos. As pontuações dos critérios são definidas de acordo com a especialidade do serviço e as notas atribuídas estão enquadradas nos conceitos: Péssimo (nota $<30)$, Insuficiente $(30 \leq$ nota $<$ $50)$, Regular $(50 \leq$ nota $<70)$, Bom $(70 \leq$ nota $<90)$ e Excelente (nota $\geq 90)$.

Para a empresa contratante analisada, as avaliações realizadas pela fiscalização (no mínimo trimestralmente para cada contrato) que forem consideradas insatisfatórias, ou seja, com conceitos Regular, Insuficiente ou Péssimo, poderão ter o contrato rescindido e ter a sua participação comprometida em futuros processos licitatórios. Uma avaliação com os conceitos Péssimo ou Insuficiente ou duas avaliações com o conceito Regular inviabilizará a presença do fornecedor em posteriores processos de contratação.

Como o objetivo deste artigo é analisar, a partir dos contratos rescindidos e suas avaliações, quais são os critérios que têm participação mais representativa para a rescisão de contratos, foram adotados os seguintes critérios de avaliação: Gestão, Logística, Prazo, Qualidade, Recursos Humanos e SMS (Segurança, Meio Ambiente e Saúde) (Williamson, 1985; Baily et al., 2000; Slack et al., 2002; Stueland, 2004; Bowersox \& Closs, 2001). Além disso, as diversas especialidades de serviços correlatas, ou seja, que são contratadas e monitoradas observando-se características similares, foram consolidadas em quatros tipos de serviços: Construção, Montagem e Manutenção Industrial; Exploração e Produção; Segurança, Meio Ambiente e Saúde (SMS); e Serviços Gerais.

Como exemplo de Construção, Montagem e Manutenção industrial estão os serviços: estudos e projetos; construção e manutenção industrial de plantas de produção em caldeiraria; elétrica; guindastes; instrumentação; limpeza química; limpeza de tanques; mecânica; motores; turbinas; e usinagem. Para Exploração e Produção estão serviços como: mergulho e operação de ROV (veículos operados remotamente); operação de sondas; operação; e manutenção de equipamentos submarinos e perfuração de poços. Para SMS estão serviços como: análises (físicas, microbiológicas, químicas e toxicológicas); brigadas de incêndio; gestão de resíduos; impacto ambiental; e saúde ocupacional. Por último, Serviços Gerais engloba: alimentação; conservação predial; limpeza industrial; recepção e vigilância; transportes rodoviários; movimentação de cargas; construção de vias de acesso e edifícios; oleodutos; e gasodutos terrestres.

Uma vez que as avaliações dos fornecedores constituem parte crucial na decisão de rescisão ou vigência do vínculo contratual da empresa, pressupõe-se um esforço dos fornecedores para a prestação de bons serviços traduzidos em boas avaliações. Consequentemente, espera-se uma relação negativa entre as notas das avaliações e a probabilidade de um contrato ser rescindo. Ou seja, contratos com maior qualidade têm menores chances de serem unilateralmente rescindidos pela empresa estudada. 


\subsection{Dados Empíricos e o Modelo Proposto}

A partir da coleta de dados, realizou-se a distribuição dos contratos encerrados por especialidade de serviços e a forma de encerramento desses contratos para facilitar a análise das variáveis, conforme demonstra a Tabela 1. O Painel A apresenta os percentuais da quantidade e o valor de contratos encerrados no período analisado, segregado por especialidade de serviços. Já o Painel B apresenta a distribuição das formas de encerramento desses contratos.

Duas especialidades de serviços apresentam maior quantidade de contratos com 32,23\% cada uma, são elas: Construção, Montagem e Manutenção Industrial e Serviços Gerais, que estão descritas no Painel A da Tabela 1. No mesmo sentido, observa-se que as formas de encerramento dos contratos estão demonstradas no Painel B da Tabela 1, que apresenta elevado percentual de contratos rescindidos, sendo $7,69 \%$ da quantidade e $10,82 \%$ nos valores dos contratos encerrados no período analisado (1/1/2006 e até 31/12/2014).

Tabela 1

Distribuição dos contratos por especialidade e formas de encerramento de contrato

\begin{tabular}{ccc}
\hline \multicolumn{3}{c}{ Painel A: Distribuição dos contratos por especialidade } \\
\hline Especialidade dos serviços & (\%) quantidade & (\%) valor \\
\hline Construção, montagem e manutenção industrial & $32,23 \%$ & $29,27 \%$ \\
Exploração e produção & $20,15 \%$ & $18,88 \%$ \\
Segurança, meio ambiente e saúde & $15,38 \%$ & $5,77 \%$ \\
Serviços gerais & $32,23 \%$ & $46,08 \%$ \\
\hline Total Geral & $100,00 \%$ & $100,00 \%$ \\
\hline Painel B: Formas de encerramento de contrato & \\
\hline Formas de encerramento do contrato & (\%) quantidade & $(\%)$ valor \\
\hline Rescisão & $7,69 \%$ & $10,82 \%$ \\
Distrato & $1,83 \%$ & $0,92 \%$ \\
Encerramento normal & $90,48 \%$ & $88,26 \%$ \\
\hline Total Geral & $100,00 \%$ & $100,00 \%$ \\
\hline
\end{tabular}

Fonte: elaborado pelo autor.

Os contratos encerrados no período por encerramento normal ou rescisão tiveram suas informações organizadas com o intuito de representar as variáveis de forma estruturada e fidedigna. Para analisar a probabilidade de um contrato de serviço ser rescindido a partir da influência de critérios de avaliação de desempenho, propôs-se o seguinte modelo por meio de regressão logística com dados em painel desbalanceado.

$$
\text { Rescisão }_{i t}=\beta_{1} \text { Gestão }_{i t}+\beta_{2} \text { Logística }_{i t}+\beta_{3} \text { Prazo }_{i t}+\beta_{4} \text { Qualidade }_{i t}+\beta_{5} R H_{i t}+\beta_{6} S M S_{i t}+\varepsilon_{i t}
$$

A variável dependente Rescisão é binária e assume o valor um (1) se no i-ésimo contrato foi observada a rescisão e o valor zero (0), caso contrário, as demais variáveis (Logística, Gestão, Prazo, Qualidade, RH e SMS) são independentes e representam a pontuação de 0 a 100 pontos observada na t-ésima avaliação do i-ésimo contrato. Nas regressões marginais, para cada critério de avaliação foram conduzidas análises considerando-se, além da média e da mediana, o primeiro quartil das avaliações. Nesse caso, o primeiro quartil foi considerado para que pudesse ser verificada a sensibilidade dos resultados com relação às notas mais baixas atribuídas ao respectivo contrato durante a sua fase de vigência. Análises baseadas apenas na média e/ou mediana poderiam desconsiderar informações relevantes e presentes em avaliações anteriores à rescisão contratual. 


\subsection{Mensuração de Variáveis}

A seguir são apresentadas as variáveis dependentes e independentes a serem utilizadas no modelo proposto.

\subsubsection{Variável dependente: Rescisão}

A Rescisão contratual ocorre quando uma das partes contratantes não cumpre satisfatoriamente a sua parte (Pereira, 2003; Gasparini, 2007; Di Pietro, 2008) e esta provoca aumento nos custos de transação (Williamson, 1985; Hart \& Moore, 1990; Tirole, 2007) para ambas as partes, tais como: financeiros, jurídicos e operacionais (Basel Committee on Banking Supervision, 2005). No caso presente, que analisa a influência das avaliações na probabilidade de um contrato ser rescindido ou não, definiu-se a variável dependente (Rescisão) como sendo igual a 1 , caso o contrato tenha sido rescindido, e igual a 0 , caso contrário.

O objetivo é identificar para os contratos em que ocorreram a rescisão contratual quais foram os critérios (variáveis independentes) que mais influenciaram para a referida rescisão contratual. Espera-se que contratos com maiores pontuações nas avaliações, conforme os critérios avaliados, possam ter menor probabilidade de ser rescindido.

\subsubsection{Variáveis independentes: Critérios de Avaliação}

\subsubsection{Critério 01: Gestão}

O critério de avaliação de desempenho Gestão contempla itens como, por exemplo, gestão administrativa, planejamento, desempenho administrativo e financeiro. São pontuados: organização, adequação ao planejamento, desempenho administrativo e desempenho financeiro. Nesse critério, é efetuado o monitoramento da situação financeira do fornecedor para identificar o cumprimento de suas obrigações com seus empregados, fornecedores, financiamentos bancários, pagamentos de impostos, entre outros.

\subsubsection{Critério 02: Logística}

O critério de avaliação de desempenho Logística contempla itens como: almoxarifado, equipamentos, transporte, instalações, materiais e oficina. São pontuados: quantidade, qualidade, condições de funcionamento, manutenção e preservação e condições de armazenagem (Benetti, Girardi \& Cortes, 2008; Chow, Heaver \& Henriksson, 1994) Nesse critério é efetuado o monitoramento das condições de apoio logístico para a execução dos serviços contratados.

\subsubsection{Critério 03: Prazo}

O critério de avaliação de desempenho Prazo avalia o cumprimento dos prazos contratados e acordados (Atkinson, 1999; De Wit, 1988; Shenhar, Dvir, Levy \& Maltz, 2001). Nesse critério, é efetuado o monitoramento do prazo da entrega dos serviços, e dos prazos parciais acordados, tais como: mobilização/ desmobilização, entrega de documentos legais, realização parcial dos serviços, entre outros. 


\subsubsection{Critério 04: Qualidade}

O critério de avaliação de desempenho Qualidade (Atkinson, 1999; De Wit, 1988; Kumar \& Wolf, 1992) contempla itens como: qualidade dos serviços, sistemas de qualidade e instrumento de controle de qualidade. São pontuados: adequação ao sistema de serviços, treinamentos, resultados da qualidade, aferição/calibração e retrabalhos. Nesse critério, é efetuado o monitoramento da qualidade dos serviços prestados pela contratada para verificar a aderência à conformidade legal dos procedimentos e evitar alocação indevida de recursos para a realização de retrabalhos, entre outros.

\subsubsection{Critério 05: RH (Recursos Humanos)}

O critério de avaliação de desempenho RH (Recursos Humanos) contempla itens como: supervisão, gerência, execução, inspeção e condições de trabalho (Lacombe \& Albuquerque, 2008). São pontuados: liderança e controle, quantidade de profissionais, qualificação e apoio logístico. Nesse critério, é efetuado o monitoramento da qualificação dos profissionais alocados para a execução contratual, incluindo os gerentes e supervisores, além, do apoio logístico necessário para o cumprimento das condições contratadas.

\subsubsection{Critério 06: SMS (Segurança, Meio Ambiente e Saúde)}

O critério de avaliação de desempenho SMS (Segurança, Meio Ambiente e Saúde) (Kumar \& Wolf, 1992; Shenhar et al., 2001) é responsável pela avaliação das condições de SMS da contratada durante a prestação dos serviços. Nesse critério, é efetuado o monitoramento das condições contratuais, tais como: quantidade e qualidade dos acidentes ocorridos na execução dos serviços, cumprimentos às exigências de segurança, taxa de ocorrência de absenteísmo, observância às exigências legais para a preservação do meio ambiente, como, por exemplo, descarte de resíduos, entre outros.

\section{Resultados}

\subsection{Estatística Descritiva}

A Tabela 2 apresenta a distribuição dos tipos de encerramento dos contratos por especialidade de serviços que ocorreram no período de 1/1/2006 a 31/12/2014. A rescisão ocorre unilateralmente pela empresa quando a contratada não cumpre a sua parte.

É possível constatar que as rescisões contratuais estão concentradas nos contratos de Serviços Gerais (48\% das rescisões ou 3,66\% do total de contratos encerrados) e Construção, Montagem e Manutenção Industrial (38\% das rescisões ou 2,93\% do total de contratos encerrados). Uma potencial explicação desse fato decorre da existência de maior quantidade de contratos nessas especialidades (32,23\%). 
Tabela 2

Especialidades por tipo de encerramento

\begin{tabular}{clcccc}
\hline \multirow{2}{*}{$\begin{array}{c}\text { Contratos } \\
\text { rescindidos }\end{array}$} & \multicolumn{1}{c}{ Especialidade de serviços } & $\begin{array}{c}(\mathbf{\%}) \\
\text { quantidade } \\
\text { encerrados }\end{array}$ & $\begin{array}{c}\mathbf{( \% )} \\
\text { valor } \\
\text { encerrados }\end{array}$ & $\begin{array}{c}\text { (\%) } \\
\text { quantidade } \\
\text { rescindidos }\end{array}$ & $\begin{array}{c}\text { (\%) } \\
\text { valor } \\
\text { rescindidos }\end{array}$ \\
\hline \multirow{2}{*}{ Rescisão } & $\begin{array}{l}\text { Construção, montagem e } \\
\text { manutenção industrial }\end{array}$ & $2,93 \%$ & $3,44 \%$ & $38,10 \%$ & $31,79 \%$ \\
\cline { 2 - 6 } & Exploração e produção & $0,73 \%$ & $0,38 \%$ & $9,49 \%$ & $3,51 \%$ \\
\cline { 2 - 6 } & Segurança, meio ambiente e saúde & $0,37 \%$ & $0,05 \%$ & $4,81 \%$ & $0,46 \%$ \\
\cline { 2 - 6 } & Serviços gerais & $3,66 \%$ & $6,95 \%$ & $47,59 \%$ & $64,23 \%$ \\
\hline
\end{tabular}

Dados da pesquisa: elaborado pelo autor.

A seguir, procurou-se calcular a média das avaliações dos fornecedores nos contratos rescindidos. A Tabela 3 apresenta a média, desvio padrão e mediana dos critérios avaliados entre os contratos rescindidos sem discriminar por especialidade. Os dados sugerem que os contratos rescindidos apresentam menores notas e maior dispersão das avaliações, o que indica a existência de possível correlação entre a classificação de um contrato a ser rescindido e suas notas.

Tabela 3

Estatísticas descritivas dos critérios por contrato rescindido

\begin{tabular}{|c|c|c|c|}
\hline Classificação / Estatística & Média & Desvio Padrão & Mediana \\
\hline Logística & 63,2 & 28,2 & 72,0 \\
\hline Gestão & 61,8 & 28,1 & 67,0 \\
\hline Prazo & 39,4 & 36,7 & 34,0 \\
\hline Qualidade & 66,2 & 25,6 & 67,0 \\
\hline $\mathrm{RH}$ & 63,5 & 25,9 & 66,7 \\
\hline SMS & 79,9 & 24,4 & 90,0 \\
\hline
\end{tabular}

Fonte: elaborado pelo autor.

A Tabela 3 apresenta, entretanto, evidências de que mesmo contratos rescindidos podem possuir elevadas notas em determinados critérios, tais como o SMS, por exemplo. Observa-se duas potenciais explicações para tal fato. A primeira é que mesmo contratos insatisfatórios podem conseguir boas notas em SMS devido ao comprometimento dos fornecedores. Segundo, poderá ocorrer um comportamento oportunista dos fornecedores que procuram boas notas nos critérios mais fáceis com o intuito de aumentar a média geral da avaliação.

Os 273 contratos analisados tiveram 19.613 avaliações de desempenho, que foram realizadas pela fiscalização, no mínimo, trimestralmente para cada contrato. Isto é, todos os contratos possuem pelo menos uma avaliação a cada 3 meses e se um contrato possui mais de uma avaliação, esta também foi considerada a fim de evitar perda de informação. Observa-se que cerca de $21 \%$ das avaliações estão com conceitos insatisfatórios (nota $<70)$.

Os fornecedores que são avaliados com conceitos inferiores ao conceito "Bom" $(<70)$ poderão ensejar na exclusão do referido fornecedor em novos processos de contratação. Essa exclusão decorre de apenas uma ocorrência nos conceitos Péssimo e Insuficiente e para duas ou mais ocorrências para o conceito Regular. Além disso, o fornecedor com tais conceitos deve elaborar plano para a melhoria na qualidade dos serviços sob pena de ter o contrato rescindido. 
A Tabela 4 apresenta as frequências, em percentual, de cada avaliação nas especialidades de serviços. Inicialmente, é possível observar que quase $20 \%$ dos contratos possuem notas insatisfatórias, o que pode significar potenciais custos transacionais para a empresa no futuro, caso necessite rescindir ou renegociar os contratos.

Além disso, a Tabela 4 demonstra que cerca de $25 \%$ dos conceitos da especialidade Serviços Gerais estão com resultados abaixo de 70\%, o que explica o elevado percentual de rescisões contratuais nesse tipo de serviço. Análise similar pode ser feita na especialidade de Construção, Montagem e Manutenção Industrial.

Tabela 4

Distribuição dos conceitos por especialidade

\begin{tabular}{|c|c|c|c|c|c|c|c|}
\hline \multirow{2}{*}{\multicolumn{2}{|c|}{ Consolidada por Critério }} & \multicolumn{6}{|c|}{ Conceito da Avaliação } \\
\hline & & \multirow{2}{*}{$\begin{array}{c}\begin{array}{c}\text { Péssimo } \\
<30\end{array} \\
8,32 \%\end{array}$} & \multirow{2}{*}{ 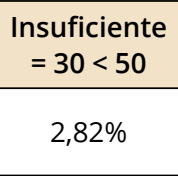 } & \multirow{2}{*}{$\begin{array}{c}\begin{array}{c}\text { Regular } \\
=50<70\end{array} \\
11,62 \%\end{array}$} & \multirow{2}{*}{$\begin{aligned} & \begin{array}{c}\text { Bom } \\
=\end{array} \\
& 20<90 \\
& 23,87 \%\end{aligned}$} & \multirow{2}{*}{$\begin{array}{c}\begin{array}{c}\text { Excelente } \\
=>90\end{array} \\
53,37 \%\end{array}$} & \multirow{2}{*}{$\begin{array}{c}\text { Total } \\
100,00 \%\end{array}$} \\
\hline $\begin{array}{l}\text { C\& M e Manutenção } \\
\text { Industrial }\end{array}$ & $(\%)$ & & & & & & \\
\hline Exp. e Produção & $(\%)$ & $2,60 \%$ & $2,67 \%$ & $10,07 \%$ & $28,19 \%$ & $56,47 \%$ & $100,00 \%$ \\
\hline SMS & $(\%)$ & $5,67 \%$ & $2,07 \%$ & $11,08 \%$ & $25,49 \%$ & $55,70 \%$ & $100,00 \%$ \\
\hline Serviços gerais & $(\%)$ & $10,17 \%$ & $3,26 \%$ & $11,57 \%$ & $25,02 \%$ & $49,99 \%$ & $100,00 \%$ \\
\hline Total & $\begin{array}{c}\text { Quant } \\
(\%)\end{array}$ & $\begin{array}{c}1555 \\
7,93 \%\end{array}$ & $\begin{array}{c}568 \\
2,90 \%\end{array}$ & $\begin{array}{c}2219 \\
11,31 \%\end{array}$ & $\begin{array}{c}4928 \\
25,13 \%\end{array}$ & $\begin{array}{c}10343 \\
52,74 \%\end{array}$ & $\begin{array}{c}19613 \\
100,00 \%\end{array}$ \\
\hline
\end{tabular}

Fonte: elaborado pelo autor.

A Tabela 5 apresenta a distribuição nas especialidades de serviços, em percentual, de cada critério avaliado. Nessa é possível visualizar o percentual de avaliações em cada critério por especialidade, a qual demonstra a maior concentração de avaliações no critério Recursos Humanos $(25,8 \%)$, seguido do critério Logística $(21,8 \%)$. O critério de avaliação Recursos Humanos está presente em praticamente todos os contratos de serviços. Além disso, a Tabela 5 evidencia que nem todos os contratos são avaliados nos mesmos critérios. Se este fosse o caso, então esperaríamos uma distribuição equitativa entre as especialidades e entre os critérios de avaliação.

Tabela 5

\section{Distribuição das especialidades por critérios}

\begin{tabular}{lcccccc}
\hline Critério avaliado & $\mathbf{( \% )}$ & $\begin{array}{c}\text { C\&M, manut. } \\
\text { industrial }\end{array}$ & $\begin{array}{c}\text { Exploração e } \\
\text { produção }\end{array}$ & SMS & Serviços gerais & Total \\
\hline Gestão & $(\%)$ & 36,42 & 12,66 & 12,01 & 38,92 & 100 \\
\hline Logística & $(\%)$ & 35,65 & 13,52 & 5,09 & 45,75 & 100 \\
\hline Prazo & $(\%)$ & 35,46 & 16,24 & 15,96 & 32,34 & 100 \\
\hline Qualidade & $(\%)$ & 36,33 & 17,83 & 8,95 & 36,89 & 100 \\
\hline Recursos humanos & $(\%)$ & 34,89 & 15,41 & 10,5 & 39,2 & 100 \\
\hline SMS & $(\%)$ & 38,12 & 15,7 & 10,02 & 36,16 & 100 \\
\hline & Quant & 7.056 & 2.959 & 1.887 & 7.711 & 19.613 \\
& $(\%)$ & 35,98 & 15,09 & 9,62 & 39,32 & 100 \\
\hline
\end{tabular}

Fonte: elaborado pelo autor. 
Por fim, a Tabela 6 apresenta a distribuição dos conceitos de avaliação, em percentual, nos critérios analisados. Novamente, quase $20 \%$ de todos os contratos possuem notas insatisfatórias (menor que 70). Ressalta-se que a variabilidade das notas nos permite analisar peculiaridades tanto de especialidades quanto de critérios, como feito posteriormente.

Especificamente, destaca-se que o critério Prazo teve cerca de 35\% das avaliações como insatisfatórias enquanto que, por outro lado, o critério SMS foi o que apresentou o menor percentual de insatisfação, cerca de $12 \%$ de resultados abaixo do esperado.

Tabela 6

Distribuição dos conceitos por critério

\begin{tabular}{|c|c|c|c|c|c|c|c|}
\hline \multirow{2}{*}{\multicolumn{2}{|c|}{ Consolidada por Critério }} & \multicolumn{6}{|c|}{ Conceito da Avaliação } \\
\hline & & \multirow{2}{*}{$\begin{array}{c}\text { Péssimo } \\
<30 \\
7,82 \%\end{array}$} & \multirow{2}{*}{$\begin{array}{c}\begin{array}{c}\text { Insuficiente } \\
=30<50\end{array} \\
2,56 \%\end{array}$} & \multirow{2}{*}{$\begin{array}{c}\begin{array}{c}\text { Regular } \\
=50<70\end{array} \\
8,89 \%\end{array}$} & \multirow{2}{*}{$\begin{aligned} & \begin{array}{c}\text { Bom } \\
=\end{array} \\
& 70<90 \\
& 18,70 \%\end{aligned}$} & \multirow{2}{*}{$\begin{array}{c}\begin{array}{c}\text { Excelente } \\
=>90\end{array} \\
62,03 \%\end{array}$} & \multirow{2}{*}{$\begin{array}{c}\text { Total } \\
100,00 \%\end{array}$} \\
\hline Gestão & $(\%)$ & & & & & & \\
\hline Logística & $(\%)$ & $7,10 \%$ & $2,74 \%$ & $10,87 \%$ & $23,27 \%$ & $56,01 \%$ & $100,00 \%$ \\
\hline Prazo & (\%) & $11,91 \%$ & $6,03 \%$ & $16,81 \%$ & $32,77 \%$ & $32,48 \%$ & $100,00 \%$ \\
\hline Qualidade & (\%) & $7,58 \%$ & $2,90 \%$ & $12,37 \%$ & $28,12 \%$ & $49,03 \%$ & $100,00 \%$ \\
\hline $\mathrm{RH}$ & $(\%)$ & $10,70 \%$ & $2,79 \%$ & $12,60 \%$ & $26,96 \%$ & $46,95 \%$ & $100,00 \%$ \\
\hline SMS & (\%) & $1,74 \%$ & $1,95 \%$ & $7,68 \%$ & $24,02 \%$ & $64,60 \%$ & $100,00 \%$ \\
\hline Total & $\begin{array}{c}\text { Quant } \\
\text { (\%) }\end{array}$ & $\begin{array}{c}1555 \\
7,93 \%\end{array}$ & $\begin{array}{c}568 \\
2,90 \%\end{array}$ & $\begin{array}{c}2219 \\
11,31 \%\end{array}$ & $\begin{array}{c}4928 \\
25,13 \%\end{array}$ & $\begin{array}{c}10343 \\
52,74 \%\end{array}$ & $\begin{array}{c}19613 \\
100,00 \%\end{array}$ \\
\hline
\end{tabular}

Fonte: elaborado pelo autor.

Em síntese, as análises descritivas discutidas acima sugerem relevância amostral dos contratos rescindidos tanto em valor contratado quanto em quantidade de contratos (Tabela 2). Como esperado, os contratos rescindidos possuem notas menores em média, além de alta variabilidade (Tabela 3), o que pode sugerir peculiaridades de determinadas especialidades ou a forma como as notas são atribuídas. Vale destacar que os contratos rescindidos ainda apresentaram médias satisfatórias em SMS, o que pode sugerir a eficiência dos fornecedores no cumprimento das demandas da firma, no que tange a esse critério, ou um comportamento oportunista dos fornecedores em maximizar as notas de critérios com menores exigências.

Além disso, ressalta-se o elevado número de avaliações dos fornecedores com notas insatisfatórias (quase 20\%, Tabela 4 e Tabela 6), o que garante a variabilidade dos dados e das análises. Por fim, vale lembrar que nem todos os contratos, mesmo os da mesma especialidade, são avaliados pelos mesmos critérios, o que pode sugerir maior variabilidade na análise (Tabela 5).

A seguir, realizou-se uma análise multivariada do efeito das avaliações dos fornecedores, na chance de um contrato ser rescindo, a fim de garantir robustez às análises efetuadas até então.

\subsection{Resultado do Modelo}

O modelo utilizado para estudar a influência das pontuações insatisfatórias nas avaliações de desempenho dos fornecedores na probabilidade de um contrato ser rescindido ou não está representado abaixo:

$$
\text { Rescisão }_{i t}=\beta_{1} \text { Gestão }_{i t}+\beta_{2} \text { Logística }_{i t}+\beta_{3} \text { Prazo }_{i t}+\beta_{4} \text { Qualidade }_{i t}+\beta_{5} R H_{i t}+\beta_{6} S M S_{i t}+\varepsilon_{i t}
$$


A Tabela 7 apresenta, em um primeiro momento, a estatística descritiva dos critérios avaliados. Por um lado, os resultados mostram que, em média, os contratos são classificados como satisfatórios, o que sugere uma boa política de terceirização da empresa. Tal argumento é fortalecido pela análise da distribuição dos dados, em geral, mais de 75\% (p25=primeiro quartil) dos contratos possuem algum critério com média Satisfatória. Por outro lado, aproximadamente 25\% dos critérios avaliados apresentam alguma avaliação Insatisfatória (nota abaixo de 70 pontos), em um total de 851 das 3.405 avaliações observadas. Esse alto percentual apresenta indícios de possíveis fragilidades do processo de terceirização.

Tabela 7

Estatística descritiva por critérios de avaliação

\begin{tabular}{lccccccc}
\hline Critérios & Média & $\begin{array}{c}\text { Desvio } \\
\text { Padrão }\end{array}$ & p1 & p25 & Mediana & p75 & p99 \\
\hline Logística & 80 & 19 & 7 & 70 & 83 & 97 & 100 \\
\hline Gestão & 78 & 21 & 1 & 70 & 80 & 95 & 100 \\
\hline Prazo & 72 & 29 & 1 & 60 & 80 & 95 & 100 \\
\hline Qualidade & 79 & 18 & 14 & 70 & 80 & 93 & 100 \\
\hline RH & 77 & 18 & 16 & 68 & 80 & 90 & 100 \\
\hline SMS & 86 & 16 & 32 & 78 & 90 & 100 & 100 \\
\hline
\end{tabular}

Fonte: elaborado pelo autor.

Em uma análise individualizada de cada critério, a partir da Tabela 7, é possível identificar a heterogeneidade das avaliações dentro dos diferentes tipos de contratos. O critério Prazo tem sido o responsável pelas menores médias e pelo maior desvio padrão dentre todos os critérios de avaliação. Além disso, verifica-se que critérios relacionados à Logística e ao RH são os mais recorrentes nas avaliações dos fornecedores, seguidos pelos critérios de Qualidade e Gestão.

A Tabela 8 apresenta os resultados estimados via logit em dados em painel desbalanceado que foram propostos no modelo acima. Nos resultados de regressão logística apresentados, todas as avaliações de todos os contratos foram utilizadas para fins de análise. Os efeitos marginais estão reportados na Tabela 8. Verifica-se o ajuste geral do modelo ao analisar a Prob>chi2. É possível observar que, a 1\%, rejeita-se a hipótese nula em que o modelo não é significativo, indicando que a rescisão dos contratos ocorre em função das pontuações avaliadas nos critérios.

Uma peculiaridade do modelo logit é que os coeficientes estimados não possuem a interpretação direta do efeito marginal das variáveis independentes na variável dependente. Os coeficientes, entretanto, ajudam a indicar o sinal da correlação das variáveis e podem indicar uma ordem do efeito marginal. No modelo em questão, descrito na Tabela 8 , observa-se a correlação negativa, em quase todos os critérios, em relação à classificação do contrato (Painel A e Painel B - $1^{\text {a }}$ coluna). Ou seja, uma maior pontuação na avaliação resultaria em menor probabilidade da rescisão contratual.

A Tabela 8, no Painel A, apresenta os resultados estimados que foram propostos no modelo logit. Já o Painel B apresenta a correlação entre os critérios avaliados. 
Tabela 8

Resultados do modelo logit em dados de painel desbalanceado

\begin{tabular}{llccc}
\hline \multicolumn{5}{c}{ Painel A: Modelo logit (Coeficientes brutos) } \\
\hline Classificação & Coeficientes & Erro Padrão & $\mathrm{Z}$ & $\mathrm{P}>|\mathrm{z}|$ \\
\hline Gestão & -0.00325 & $(0.00701)$ & -0.46 & 0.643 \\
\hline Logística & $-0.02020^{\star \star \star}$ & $(0.00749)$ & -2.70 & 0.007 \\
\hline Prazo & $-0.02350^{\star \star \star}$ & $(0.00472)$ & -4.97 & 0.000 \\
\hline Qualidade & -0.00282 & $(0.00711)$ & -0.40 & 0.692 \\
\hline RH & -0.00519 & $(0.00868)$ & -0.60 & 0.550 \\
\hline SMS & 0.01120 & $(0.00744)$ & 1.51 & 0.130 \\
\hline Wald chi(6) & 258.33 & & & \\
\hline Prob > chi2 & 0.0000 & & & \\
\hline
\end{tabular}

\begin{tabular}{|c|c|c|c|c|c|c|c|}
\hline \multicolumn{8}{|c|}{ Painel B: Tabela de correlação entre os critérios } \\
\hline Correlação & Classificação & Logística & Gestão & Prazo & Qualidade & RH & SMS \\
\hline Classificação & 1 & & & & & & \\
\hline Logística & $-0.2278^{*}$ & 1 & & & & & \\
\hline Gestão & $-0.1867 *$ & $0.3266^{*}$ & 1 & & & & \\
\hline Prazo & $-0.2196 *$ & $0.1485^{*}$ & $0.3460 *$ & 1 & & & \\
\hline Qualidade & $-0.1477^{*}$ & $0.3067^{*}$ & $0.3146 *$ & $0.3362^{*}$ & 1 & & \\
\hline $\mathrm{RH}$ & $-0.1654^{*}$ & $0.3970 *$ & $0.3962 *$ & $0.2946 *$ & $0.3687 *$ & 1 & \\
\hline SMS & $-0.1346^{*}$ & $0.3022^{*}$ & $0.1797 *$ & $0.0929 *$ & $0.1603^{*}$ & 0.2011 * & 1 \\
\hline
\end{tabular}

$* * * p<0.01, * * p<0.05, * p<0.1$

Fonte: elaborado pelo autor

\subsubsection{Efeito marginal por critério de avaliação}

Para buscar melhor identificar o efeito dos critérios na probabilidade da rescisão do contrato, e não apenas obter a correlação entre as variáveis, estimou-se o efeito marginal das variáveis independentes sobre a classificação do contrato mantendo-se as outras variáveis fixadas na média, na mediana e no primeiro quartil.

A Tabela 9 apresenta o efeito marginal por critério de avaliação. É possível observar que apenas os critérios que afetaram a probabilidade da rescisão contratual foram Prazo e Logística. Esses resultados sugerem que, na média (mediana e $1^{\circ}$ quartil), um aumento na pontuação na avaliação desses critérios tem um maior efeito na redução da probabilidade de classificação insatisfatória para um contrato.

A constatação que os critérios Logística e Prazo apresentam maior influência nas rescisões contratuais corrobora o entendimento de (Suslick, 2002; Kaiser \& Pulsipher, 2004) que afirmam que o segmento de exploração e produção de petróleo possui altos riscos empresariais atribuídos às incertezas quanto ao resultado e elevados custos, ratificando a importância do cumprimento das obrigações contratuais, especialmente os prazos negociados. 
Os resultados apresentados na Tabela 9 também sugerem a relevância das avaliações e o monitoramento dos fornecedores, a fim de evitar rescisões contratuais e potenciais custos de transação. Estes resultados vão ao encontro de trabalhos como o de Greenwood e Yates (2006), Eriksson (2008) e Gomes (2014). Entretanto, diferenciam destes ao focar no processo de rescisão contratual ao invés do processo de contratação.

Tabela 9

Estimação do efeito marginal por critério de avaliação

\begin{tabular}{|c|c|c|c|}
\hline Variáveis (Critérios) & Efeito Marginal média & Efeito Marginal mediana & Efeito Marginal $1^{\circ}$ quartil \\
\hline \multirow{2}{*}{ Gestão } & -0.000132 & -0.000110 & -0.000223 \\
\hline & $(0.000286)$ & $(0.000237)$ & $(0.000483)$ \\
\hline \multirow{2}{*}{ Logística } & $-0.000822 * * *$ & $-0.000683 * * *$ & $-0.00139 * * *$ \\
\hline & $(0.000311)$ & $(0.000256)$ & $(0.000504)$ \\
\hline \multirow{2}{*}{ Prazo } & $-0.000953^{* * *}$ & $-0.000793^{* * *}$ & $-0.00161 * * *$ \\
\hline & $(0.000183)$ & $(0.000160)$ & $(0.000319)$ \\
\hline \multirow{2}{*}{ Qualidade } & -0.000115 & $-9.53 e-05$ & -0.000193 \\
\hline & $(0.000290)$ & $(0.000241)$ & $(0.000489)$ \\
\hline \multirow{2}{*}{$\mathrm{RH}$} & -0.000211 & -0.000175 & -0.000356 \\
\hline & $(0.000353)$ & $(0.000295)$ & $(0.000597)$ \\
\hline \multirow{2}{*}{ SMS } & 0.000457 & 0.000380 & 0.000771 \\
\hline & $(0.000299)$ & $(0.000247)$ & $(0.000518)$ \\
\hline
\end{tabular}

$* \star * p<0.01, * * p<0.05, * p<0.1$

Fonte: elaborado pelo autor.

\subsubsection{Efeito marginal por especialidade}

Em uma análise mais específica da empresa, evidenciou-se a necessidade de se analisar as pontuações dos critérios nos contratos por especialidade de serviços, uma vez que determinadas especialidades possuem demandas e gargalos diferentes das demais. A ausência desta análise pode negligenciar efeitos específicos de cada especialidade. Por exemplo, contratos da especialidade Serviços Gerais podem ter pontuações no critério Logística diferentes de contratos de Construção, Montagem e Manutenção Industrial. Sendo assim, torna-se relevante analisar cada especialidade para observar o impacto marginal de cada critério. A Tabela 10 apresenta o efeito marginal do modelo. Das quatro especialidades definidas no trabalho, duas não apresentaram contratos rescindidos, o que inviabilizou a estimação dos modelos para estas,uma vez que não houve alteração na variável dependente ( $y=1$ contrato rescindido). Foram elas: Segurança, Meio Ambiente e Saúde e Exploração e Produção. Isso representa que tais especialidades possuem boas avaliações e que o aumento da nota de avaliação não reduz a probabilidade de rescisão.

A Tabela 10 apresenta o efeito marginal por especialidade de serviços. Os resultados sugerem que na especialidade Construção, Montagem e Manutenção Industrial os critérios Logística e Prazo apresentam maior magnitude. Na especialidade Serviços Gerais, a maior magnitude está nos critérios Gestão e Prazo. 
Tabela 10

Estimação do efeito marginal por especialidade de serviços

\begin{tabular}{|c|c|c|}
\hline Critérios / Especialidade & C\&M e Manut. Industrial & Serv. Gerais \\
\hline \multirow{2}{*}{ Gestão } & $0.00164 * \star$ & $-0.00117 * * *$ \\
\hline & $(0.000672)$ & $(0.000387)$ \\
\hline \multirow{2}{*}{ Logística } & $-0.00136 * * *$ & -0.000497 \\
\hline & $(0.000493)$ & $(0.000431)$ \\
\hline \multirow{2}{*}{ Prazo } & $-0.00119 * * *$ & $-0.000978^{* \star *}$ \\
\hline & $(0.000342)$ & $(0.000253)$ \\
\hline \multirow{2}{*}{ Qualidade } & 0.000288 & $-0.000666^{*}$ \\
\hline & $(0.000518)$ & $(0.000371)$ \\
\hline \multirow{2}{*}{$\mathrm{RH}$} & -0.000739 & 0.000105 \\
\hline & $(0.000563)$ & $(0.000501)$ \\
\hline \multirow{2}{*}{ SMS } & -0.000363 & $0.00129 * \star \star$ \\
\hline & $(0.000449)$ & $(0.000476)$ \\
\hline
\end{tabular}

Erro padrão está dentro de parênteses

$* * * p<0.01, * * p<0.05, * p<0.1$

Fonte: elaborado pelo autor.

A Tabela 10 apresenta o efeito marginal das especialidades Construção, Montagem e Manutenção Industrial e Serviços Gerais, respectivamente. É possível observar que as especialidades apresentam demandas e gargalos diferentes, uma vez que os critérios que possuem maior impacto na probabilidade de rescisão contratual diferem entre as especialidades. Para a especialidade Construção, Montagem e Manutenção Industrial, os critérios Logística e Prazo apresentam sinais esperados, informando que quanto maior a nota desses critérios, menor a probabilidade de um contrato ser rescindido. Por outro lado, Gestão apresenta efeito marginal positivo. Isto é, quanto maior a nota de Gestão, maior a probabilidade de rescisão contratual. Segurança, Meio Ambiente e Saúde também apresenta tal peculiaridade para a especialidade Serviços Gerais. Esses resultados se mostraram robustos à análise do efeito marginal na mediana e no $1^{\circ}$ quartil (estimações omitidas).

Em uma análise mais detalhada é possível observar que a correlação entre Gestão e a Rescisão não é significante, estatisticamente, na especialidade Construção, Montagem e Manutenção (tabela omitida). Uma das possíveis explicações para tal correlação não ser significante se dá pelas altas médias das notas dos contratos. Isto é, tanto os contratos rescindidos quanto os contratos não rescindidos possuem média alta no critério Gestão. Neste sentido, contratos com baixas notas nos demais critérios, porém com alta nota em Gestão (ou SMS, no caso da especialidade Serviços Gerais) podem indicar para a empresa contratante sobre possíveis contratos problemáticos, no futuro, ou necessidade de revisão nas cláusulas contratuais. 


\subsection{Análise dos Resultados}

A Figura 1 apresenta os resultados consolidados do presente trabalho, que teve como objetivo analisar quais são os critérios de avaliação de serviços que mais influenciam as rescisões contratuais no setor de exploração e produção de petróleo e gás.

\begin{tabular}{|c|c|c|}
\hline Item & Resultado & Explicação para os resultados \\
\hline \multirow[t]{2}{*}{ Critérios } & Prazo & $\begin{array}{l}\text { Critério com maior influência para a rescisão de contratos: } \\
\text { - } 35 \% \text { das pontuações tiveram notas insatisfatórias (abaixo de } 70 \text { pontos); } \\
\text { - No modelo logit, foi o critério que apresentou maior magnitude. Observou-se que, } \\
\text { caso o fornecedor melhore os seus resultados, aumentando em } 1 \text { ponto a nota da } \\
\text { avaliação neste critério, na média, reduzirá em 0,9\% a probabilidade de rescisão } \\
\text { contratual. }\end{array}$ \\
\hline & Logística & $\begin{array}{l}\text { Critério com a segunda maior influência para a rescisão de contratos: } \\
\text { - No modelo logit, foi o critério que apresentou a segunda maior magnitude. } \\
\text { Observou-se que, caso o fornecedor melhore os seus resultados, aumentando } \\
\text { em } 1 \text { ponto a nota da avaliação neste critério, na média, poderá reduzir em 0,8\% a } \\
\text { probabilidade de rescisão contratual. }\end{array}$ \\
\hline \multirow[b]{2}{*}{ Especialidades } & $\begin{array}{c}\text { Serviços } \\
\text { Gerais }\end{array}$ & $\begin{array}{l}\text { Especialidade de serviços com maior quantidade de rescisão de contratos: } \\
\text { - } 48 \% \text { da quantidade de contratos rescindidos (ou 3,66\% do total de contratos } \\
\text { encerrados. } \\
\text { - Na estimação do efeito marginal, observou-se que os critérios Gestão e Prazo } \\
\text { apresentaram maior impacto na probabilidade de rescisão contratual. Para ambos } \\
\text { os critérios, caso o fornecedor melhore os seus resultados em } 1 \text { ponto a nota da } \\
\text { avaliação, na média, poderá reduzir em } 1 \% \text { a probabilidade de rescisão contratual. }\end{array}$ \\
\hline & $\begin{array}{c}\text { Construção, } \\
\text { Montagem e } \\
\text { Manutenção } \\
\text { Industrial }\end{array}$ & $\begin{array}{l}\text { Especialidade de serviços com a segunda maior quantidade de rescisão de contratos: } \\
\text { - } 38 \% \text { da quantidade de contratos rescindidos (ou 2,93\% do total de contratos } \\
\text { encerrados). } \\
\text { - Na estimação do efeito marginal, observou-se que os critérios Logística e Prazo } \\
\text { apresentaram segundo maior impacto na probabilidade de rescisão contratual. } \\
\text { Caso o fornecedor melhore os seus resultados, aumentando em } 1 \text { ponto a nota } \\
\text { da avaliação nestes critérios, na média, poderá reduzir em 1\% a probabilidade de } \\
\text { rescisão contratual. }\end{array}$ \\
\hline
\end{tabular}

Figura 1. Resumo dos resultados

Nota. Fonte: elaborado pelo autor.

Os resultados se mostram relevantes porque confirmam a importância do monitoramento dos agentes nas transações econômicas como fatores relacionados aos custos de transação (i.e. rescisão contratual). Esse resultado vai ao encontro de estudos de casos como o de Greenwood e Yates (2006), Eriksson (2008) e Gomes (2014). Entretanto, diferencia-se desses ao focar no processo de rescisão contratual ao invés do processo de contratação. Além disso, as análises permitem melhor entendimento da estrutura de avaliação de contratos de uma empresa de grande porte e relevância no setor econômico brasileiro. Devido à complexidade e diversidade dos contratos presentes no estudo, espera-se, por meio deste estudo de caso, colaborar para o melhor entendimento do processo de monitoramento e gerenciamento de relações contratuais.

Entender e aperfeiçoar a gestão dos contratos por meio de ações que permitam reduzir as possíveis rescisões contratuais parece ser interessante para todas as empresas, corroborando Klein (1992), que afirma que a melhoria no desenho dos contratos irá reduzir a probabilidade de encerramento contratual de cunho oportunista. Os resultados sugerem possíveis direcionamentos de novas políticas para o aumento da eficiência dessa gestão, uma vez que identifica quais critérios possuem maior efeito na probabilidade de um contrato ser rescindido em uma empresa de exploração e produção de petróleo e gás. 


\section{Conclusões}

O presente trabalho analisou 273 contratos de serviços (e suas avaliações) nas atividades de exploração e produção de petróleo e gás com o objetivo de estudar quais são os critérios de avaliação de desempenho que têm maior influência na rescisão de contratos no referido setor. A fim de evitar viés de sobrevivência, utilizou-se apenas contratos iniciados e rescindidos no período de análise.

Por meio de análises descritivas e estimações via logit, foi possível observar um efeito dos critérios Prazo e Logística na probabilidade de rescisão contratual. Observou-se que um aumento na nota de Prazo e Logística contribui para a redução na probabilidade de rescisão contratual. Posteriormente, estendeu-se a análise dos critérios por especialidade de serviços. Foi possível observar efeitos peculiares por especialidade, confirmando as inferências de que diferentes especialidades possuem demandas distintas e, por conseguinte, diferentes modelos contratuais.

A relevância da análise dos contratos rescindidos fica evidente nos resultados da análise descritiva, os quais indicam elevado percentual de contratos rescindidos, sendo 7,69\% da quantidade e 10,82\% nos valores dos contratos encerrados no período analisado. Também foi possível constatar que as rescisões contratuais estão concentradas nos contratos de Serviços Gerais e Construção, Montagem e Manutenção Industrial. Vale destacar que aproximadamente $25 \%$ das avaliações da especialidade Serviços Gerais estão com resultados inferiores a 70 pontos, corroborando para justificar o grande percentual de rescisões contratuais nesse tipo de serviço. $\mathrm{Da}$ mesma forma, é possível observar que o critério Prazo teve cerca de 35\% das avaliações como insatisfatórias.

Os resultados sugerem a relevância do monitoramento dos agentes nas transações econômicas como fatores relacionados aos custos de transação (i.e. rescisão contratual). Esses resultados vão ao encontro de estudos de casos como o de Greenwood e Yates (2006), Eriksson (2008) e Gomes (2014). Entretanto, diferenciam-se destes ao focar no processo de rescisão contratual ao invés do processo de contratação.

Entender e aperfeiçoar a gestão dos contratos por meio de ações que permitam reduzir as possíveis rescisões contratuais parece ser interessante para todas as empresas, corroborando Klein (1992), que afirma que a melhoria no desenho dos contratos irá reduzir a probabilidade de encerramento contratual de cunho oportunista. Os resultados sugerem possíveis direcionamentos de novas políticas para o aumento da eficiência dessa gestão, uma vez que identifica quais critérios possuem maior efeito na probabilidade de um contrato ser rescindido em uma empresa de exploração e produção de petróleo e gás.

Devido à dificuldade na obtenção de dados e do baixo número de trabalhos na área de avaliação de desempenho de contratos de serviços no setor de exploração e produção de petróleo e gás, recomenda-se futuras pesquisas abordando o efeito financeiro da rescisão nos resultados das empresas, além de análise do perfil de fornecedores com intuito de avaliar a relação organizacional em contratos de terceirização. Em virtude da indisponibilidade de dados, não foram incluídos no presente estudo outras variáveis explicativas para as rescisões de contratos, como, por exemplo, aquelas embasadas na Teoria da Visão Baseada em Recursos (RBV) (Barney, 1991), além de outros controles, como a maturidade e a natureza das empresas contratadas (nacional, estrangeira, pública, privada etc.) e algumas outas variáveis de natureza contábil.

As análises feitas, entretanto, mostram-se importantes ao contribuir para a otimização da gestão dos contratos por meio da análise prévia dos fatores que levam a potenciais rescisões. Além disso, permitem melhor entendimento da estrutura de avaliação de contratos de uma empresa pertencente a um setor relevante para a economia brasileira e, especificamente, associa-se a técnicas da contabilidade gerencial de análise de projetos (contratos) e monitoramento.

A descrição da sistemática de avaliação dos fornecedores de serviços contribui tanto com a literatura de contratos quanto com os meios empresariais ao identificar os critérios utilizados na sistemática de avaliação do segmento de exploração e produção de petróleo e gás, bem como ao apresentar os resultados das avaliações das respectivas empresas do segmento. $\mathrm{O}$ acompanhamento de tais critérios pode auxiliar as tomadoras de serviços na definição de estratégias que permitam uma gestão de contratos mais eficiente. Além disso, pode fornecer informações para que os fornecedores de serviços possam avaliar e adequar seus processos de forma a permanecer atuando nesse segmento da indústria. 


\section{Referências}

Atkinson, R. (1999). Project management: cost, time and quality, two best guesses and a phenomenon, its time to accept other success criteria. International Journal of Project Management, 17(6), pp. 337342. doi: 10.1016/S0263-7863(98)00069-6

Azevedo, P. F. (2000). Nova Economia Institucional: referencial geral e aplicações para a agricultura - Agricultura em São Paulo. São Paulo: IEA, v. 47, n. 1, pp. 33-52.

Baily, P. J. H., Farmer, D., Jones, D. \& Jessop, D. (2000). Compras: princípios e administração (8a ed.). São Paulo: Atlas.

Barney, J. B. (1991). Firm resource and sustained competitive advantage. Journal of Management, 17(1), pp. 99-120. doi: 10.1177/014920639101700108

Basel Committee on Banking Supervision. International Convergence of Capital Measurement and Capital Standards. (2005). Bank for International Settlements. November. p. 140. Recuperado em 27 junho, 2015, de http://www.bis.org/publ/bcbs118.pdf.

Benetti, K., Girardi D., Rodriguez C. \& Cortes A. (2008). Modelo de avaliação de desempenho logístico de um centro de distribuição do setor supermercadista. Anais do Seminário de Administração - Empreendedorismo em Organizações, São Paulo-SP, Brasil, 11.

Bowersox, D., Closs, D. (2001). Logística empresarial. São Paulo: Atlas.

Brasil. (1998a). Decreto no 2.455, de 24 de Janeiro de 1998. Implanta a Agência Nacional do Petróleo - ANP, autarquia sob regime especial, aprova sua Estrutura Regimental e o Quadro Demonstrativo dos Cargos em Comissão e Funções de Confiança e dá outras providências. Recuperado em 05 março, 2015, de http://www.planalto.gov.br/ccivil_03/decreto/D2455.htm.

Brasil. (1998b). Decreto $n^{\circ} 2.745$, de 24 de Agosto de 1998. Aprova o Regulamento do Procedimento Licitatório Simplificado da Petróleo Brasileiro S.A. - PETROBRÁS previsto no art. 67 da Lei no 9.478, de 6 de agosto de 1997. Recuperado em 05 março, 2015, de http://www.planalto.gov.br/ccivil_03/ decreto/D2745.htm.

Chopra, S. Meindl, P. (2013). Supply Chain Management: strategy, planning, and operation (5 $\left.{ }^{\mathrm{a}} \mathrm{ed}\right)$. U.S.A.: Pearson Prentice Hall, 528.

Chow, G., Heaver, T. D. \& Henriksson, L. E. (1994). Logistics performance: definition and measurement. International Journal of Physical Distribution \& Logistics Management, Bradford, 24(1), pp. 17-28. doi: 10.1108/09600039410055981

Coase, R. H. (1937). The nature of the firm. Economica, 4(16), pp. 386-405. doi: 10.1111/j.1468-0335.1937. tb00002.x

Coriolano, A., Reis, E. \& Delgado, R. (2013). A indústria do petróleo e os modelos de contrato para exploração e produção no Brasil. Revista Eletrônica de Petróleo e Gás, 2(1).

De Wit, A. (1988). Measurement of Project Success. Journal of Project Management, 6(3). doi : 10.1016/0263-7863(88)90043-9

Di Pietro, M. H. (2008). Direito administrativo (21ª ed.). São Paulo: Atlas.

Eriksson, E. (2008). Procurement effects on coopetition in client-contractor relationships. Journal of Construction Engineering and Management, 134(2), pp. 103-111. doi: 10.1061/(ASCE)07339364(2008)134:2(103)

Fine, C. H. (2000). Clockspeed-based strategies for supply chain design1. Production and Operations Management, 9(3), pp. 213-221. 
Gasparini, D. (2007). Direito administrativo (12 ed.). São Paulo: Saraiva.

Gomes, A. C. (2014). Influência dos custos de transação na contratação através da relação de parceria: caso de fornecimento de serviços em uma empresa de construção civil. Dissertação de mestrado, FUCAPE, Vitória, ES, Brasil.

Greenwood, D, J. \& Yates, D. J. (2006) The determinants successful partnering: a transaction cost perspective. Journal of Construction Procurement, 12(1), pp. 4-22.

Hart, O. (1999). Foundations of incomplete contracts. Review of economic studies, 66(1), pp. 115-138. doi: 10.1.1.190.2074

Hart, O. \& Moore, J. (1990). Property rights and the nature of the firms. Journal of Political Economy, 98(6), pp. 1119-1158. doi:10.1086/261729

Jensen, M. \& Meckling, W. (1976). Theory of the Firm: Managerial Behavior, Agency Costs and Ownership Structure. Journal of Financial Economics, 3(4), pp. 305-360. http://dx.doi.org/10.2139/ ssrn. 94043

Kaiser, M. \& Pulsipher, A. (2004). Fiscal system analysis: Concessionary and contractual systems used in offshore petroleum arrangements. U.S. Department of the Interior, Minerals Management Service, Gulf of Mexico OCS Region, New Orleans, La. OCS Study MMS 2004-016. 78 pp.

Klein, B. (1992). Contracts and incentives: The role of contract terms in assuring performance in contract economics. Oxford.

Kumar, C. \& Wolf, C. (1992). Assessing Project Quality. Transactions of the American Associations of Cost Engineers, 2.

Lacity, M. C.; Hirschheim, R. (1993). Information System Outsourcing: myths, metaphors and realities. New Jersey: Prentice-Hall.

Lacombe, B. \& Albuquerque, L. G. (2008). Avaliação e Mensuração de resultados em gestão de pessoas: um estudo com as maiores empresas instaladas no Brasil. Revista de Administração, 43(1), pp. 5-16. doi: 10.1590/S0080-21072008000100001

Mcivor, R. (2005). The outsourcing process: strategies for evaluation and management ( $\left.1^{\mathrm{a}} \mathrm{ed}\right) . \mathrm{Cam}-$ bridge: Cambridge University Press, 338 p.

Nepomuceno, F., Suslick, S. B. (2000). Alocação de recursos financeiros em projetos de risco na exploração de petróleo. Revista de Administração de Empresas, 40(1), pp. 63-75. doi: 10.1590/S003475902000000100008

Pereira, C. M. da S. (2003). Instituições de direito civil (1 $1^{\text {a }}$ Edição Eletrônica). Rio de Janeiro.

PETROBRAS. Plano de Negócios e Gestão 2014-2018. Recuperado em 31 agosto, 2014, de http://www.petrobras.com.br/pt/quem-somos/estrategia/plano-de-negocios-e-gestao/.

Shenhar, A. J., Dvir, D., Levy, O., \& Maltz, A. C. (2001). Project Success: A Multidimensional Strategic Concept. Long Range Planning, 34: pp. 699-725. doi: 10.1016/S0024-6301(01)00097-8

Slack, N., Chambers, S. \& Johnston, R. (2002). Administração da produção (2a ed.). São Paulo: Atlas.

Stueland, V. J. (2004). Supplier evaluation: best practices and creating or improving your own evaluation. ISM's 89th Annual International Supply Management Conference Proceedings.

Suslick, S. B. (2002). Conhecer as incertezas: O desafio da indústria do petróleo. São Paulo. Recuperado em 07 setembro, 2014, de http://www.comciencia.br/reportagens/petroleo/pet20.shtml.

Tirole, J. (2007). Bounded Rationality and Incomplete Contract. University of Toulouse, Working Paper.

Van De Ven, A. H. (1976). On the nature, formation and maintenance of relations among organizations. The Academy of Management Review, 1(4), pp. 24-36. doi: 10.2307/257722 
Willcoks, L. \& Feeny, D. (1998). Core IS Capabilities for Exploiting Information Technology. Sloan Management Review, 39(3), pp. 9-21.

Williamson, O. E. (1985). The Economic Institutions of Capitalism: Firms, Markets, Relational Contracting. New York: Free Press. http://dx.doi.org/10.1007/978-3-8349-9320-5_6

Yin, R. K. (2001). Estudo de caso: planejamento e métodos (2a ed.). Porto Alegre: Bookman. 